\title{
Implications of On-line Systems Techniques for a Decentralized Research Library System
}

On-line and batch mode computer-based library systems are defined to show their basic differences. This is related to how on-line systems can provide an operating framework for the large research library, thus providing the groundwork for a national information network. This article also discusses systems design factors, operating system and application software, various geographic implications, user services, and library staff effects. Additionally, certain problems are noted which libraries face as they proceed toward design, debugging, and installation of computer-based on-line operating systems for record and information control and dissemination.

\section{On-line and Batch Mode Systems}

P Pedominant among the computerbased library systems representing the current state-of-the-art are systems operating in the batch mode. In such systems, input data are gathered for processing at stated time intervals, and required outputs are produced by the processing of these data. These outputs are usually printed or punched. Corrections, additions, or changes must wait until the next processing time. For many tasks, such as order printing, circulation card punching, and various listing functions, this mode has provided sufficiently current service on an economical basis without detriment to user services.

Certain library-user-related functions do suffer, however, because of the time lag between processing, correction, and

Mrs. Grosch is Systems Coordinator in the University of Minnesota Library. desired output when batch mode is employed. Functions such as recording receipt of periodicals, charge-out of bibliographic materials, file searching, file correcting, and timeliness of information are directly affected by the batch mode. It is highly desirable to perform these functions within the framework of an on-line computer-based information system. Such a system would permit a return to the "real-time" environment which does exist when making changes in manual systems, yet provide all operating units with access to the total record base of the library system without file duplication. Operating in an on-line mode would mean that updating of files, initiation of transactions of various types, and certain output functions would be processed in what appears to be "real-time" to the system user through the direct man/machine interface of a console unit. Such a library system can be designed today for the large, decentralized research library since hardware

112 / 
and operating system software are available for such systems. Project Ballots ${ }^{1}$ and work carried out at the University of California, Berkeley, under Professor Maron $^{2}$ show that progress in this direction is being made. In addition, our national libraries are devising standard record formats for bibliographic information as typified by Project MARC.

This on-line library system would be developed to serve library user and staff needs by creating a centralized, integrated data store of the library's bibliographic and in-process information. Such a system would operate via keyboard display consoles, data collection units, and other necessary equipment connected to a central computer over various types of communication lines. Certain tasks would be performed in the batch mode, but main emphasis of the system to serve current user needs would structure the system to require short user response time, let us say, under four-second maximum delay on a message sent in response to a console inquiry. Therefore, the on-line, integrated record system envisioned by this author in future large libraries will combine both modes of operation for maximum efficiency, service, and economy. Such a record system will be compatible to standard bibliographic information disseminated through our three national libraries, the Library of Congress, the National Library of Medicine, and the National Agricultural Library.

\footnotetext{
${ }^{1}$ Stanford University. Bibliographic automation of large library operations using a time sharing system (Project Ballots), a proposal for research and/or related activities submitted to the U.S. Commissioner of Education for support through authorization of the Bureau of Research. Principal Investigator: Allen Barnet Veaner. Project Director: Rutherford David Rogers. May 1967, granted October 1968.

${ }^{2}$ University of California, Berkeley. A study of the organization of search of bibliographic holdings records in on-line computer systems, a proposal for research and related activities submitted to the U.S. Commissioner of Education for support through authorization of the Bureau of Research. Principal Investigator: M. E. Maron. May 1967.
}

\section{System Design Factors}

No library system exists which truly integrates all of the total library operations from the original order of an item to its eventual delivery to the user. Certain of these segments are being performed by computer-based systems in various ways by many institutions. To achieve maximum benefit from an online application it is highly desirable to interface as many operations and tasks as possible, i.e., to have the system perform as much work as possible, within limits of the hardware procured. This serves to create orderliness in processing, efficiency on the part of the staff, and economical equipment utilization. For example, present circulation control systems of either operational mode record the necessary transaction information, but the machine readable input card used to record the transaction in most of these systems is not a by-product of the original book processing operation, nor are these circulation files accessible by any other means than telephoning the circulation department, consulting their file listing, or using their console for file inquiry. Further, the typical circulation file provides a record of materials charged out, temporarily in a processing department, or special stack location. This file may provide for some queuing of users to a specific bibliographic volume but does not automatically balance the waiting users among widely scattered copies which may be duplicated in the total library collection. In addition, such a batch mode circulation system does not serve as a locator tool for volumes on the shelf in a geographically decentralized library environment.

From the above example, we can see the need for integration of circulation operations with the total processing operation. To carry our example a step further, the following benefits would ac- 
crue from integrating the circulation file function:

1. determining specific location of volume;

2. determining availability by location;

3. queuing of user to item having immediate availability or shortest waiting list or time until return;

4. triggering order of additional copies according to user demand;

5. handling user cancellations by automatically shifting user queues;

6. determining storage transfers or withdrawals of volumes by their use history according to library standards;

7. full bibliographic information easily available for the issuance of recalls and overdues.

This means that the on-line library system must have at its heart a file structured to handle both bibliographic and operational data, meeting generally the following requirements:

1. bibliographic information for each volume added to the collection compatible with national systems requirements;

2. subject searching and specific entry searching capabilities;

3. library operational data, including ordering, accounting, routing, location, processing history, and management information relative to file use and transactions involving use or change of the files;

4. service file information, such as:

a. vendor name and address files,

b. borrower name and address files (probably the above two are institution-wide shared files ),

c. account or fund files,

d. user interest profiles;

5. special depth indexed bibliographic files for special subsystems such as selective dissemination in delimited subject areas.

As noted above, portions of this file may operate in a file-sharing mode so that a file connected to one central processor may be accessed for inquiry by another computer over a communication line. This can give important cost savings within an institution.

Systems design will evolve which fits individual library needs yet maintains compatibility with national bibliographic sources. Since libraries differ vastly in their accounting, processing, and subject matter, these factors, together with size and user services, will determine the system requirements. Therefore, prime systems design factors will be the structuring of the integrated data base, using as many practical economics, such as file sharing, as possible, yet carrying out required applications and allowing flexibility for further system evolution and size growth.

\section{Operating System Software}

The operating systems supplied with medium- to large-scale computers most frequently used in on-line commercial systems, enable the computer to receive, process, and transmit data to and from various communications devices connected to the system. By buffering and memory paging such software permits the computer to maximize its efficiency, handling many jobs, seemingly simultaneously. By the establishment of priorities in processing and queues of jobs waiting to be processed and then polling these queues, many users of the system can be served with minimum response times. It is the development of this operating system software together with large mass storage files which has made on-line library systems as possible today as the airline reservation systems of this type currently operating and being developed. In fact, in certain situations, on-line processing becomes more feasible from a service and cost viewpoint than any other type. This analyst believes that in years to come this will also prove true for large research libraries. 
Present developments on a national scale certainly point to the time when large libraries will become stations in a national library network system, each responsible for a segment of the world's published literature, by subject or by type. The heart of such a system would depend upon rapid communication between its stations to answer user requests. Messages consisting of bibliographic information, availability, and facsimile transmission of the document itself will be initiated through use of consoles operating as part of an on-line system. If these networks are really going to develop, machine readable data bases must be at their heart to enable remote communication and exchange of information. Therefore, it behooves large libraries to develop such systems to prepare for national interaction. As operating system software improves, a library's systems design task is strengthened so that future developments will undoubtedly offer the library a framework for even more effective systems.

Operating system software is complex, extremely expensive to develop, and up to now has been the prime responsibility of the computer manufacturer. Most installations have added their own improvements faster than they could have become available for release from the manufacturers. Libraries, as an applications user group, will be no exception to this when they operate their own computer systems or share a superscale system within their parent institutions. Libraries will find it necessary to support further operating systems development and become vocal on their requirements to the computer manufacturers. Because of the technical lag between what present hardware and software can accomplish, it may be left up to the library to undertake modifications in operating system software where needed and not wait for the manufacturer if long systems delays are to be avoided.

\section{Applications Software}

Programs designed to process information and produce required output for library staff and users will be the prime responsibility of the library systems group. Certain types of applications programs, SORT/MERGE, for example, may be written for use in the library community by cooperating libraries to achieve specially tailored printed output such as book catalogs. Filing standards presently used should be evaluated according to ease of use by the user of the catalog. When more libraries begin to depend upon computer based systems, filing standards deemed absolutely necessary are bound to result. Certainly, it is possible to program the ALA/LC filing rules, but there is a high degree of variation in present practices in most libraries. A national standard specially suited to machine processing will undoubtedly result in time through the cooperation of the three national libraries. Some, however, would feel that each library should form its own conclusions on filing and build from this point initially.

In on-line processing systems operating in a time sharing mode, a limited block of core storage will be available for each program during its execution time. Therefore, one application program characteristic will be structural modularity. Segmentation of programs, small routines, overlaying, and use of common subroutines for programs operating in on-line applications will keynote program design. Operating time efficiency and minimization of core storage required will assume increased importance. For this reason many programs may be written using assemblers rather than higher order languages.

In libraries, as in the computer industry, attempts at standardization have not really resulted in much standardization. Only recently with the formation of EBCDIC codes in use on IBM Sys- 
tem 360 equipment has the computer industry attempted to offer more than the usual 64 character set. For library use it would seem that standard codes allowing 128 characters would be minimal for representation of European alphabet languages, lower case, and of enough special symbols. With an increased use of extended character set chain printers beyond libraries, the manufacturers should be urged to base future hardware designs on eight level codes rather than the various six bit codes now used by all except IBM. It may be that libraries will want to base their systems plans and requirements on the hexadecimal code structure to enable direct encoding of up to $256 \mathrm{sep}$ arate characters. Character set developments put into practice by MARC will be watched with interest by all libraries attempting to decide upon basic encoding techniques or what hardware to buy. Certainly libraries will be faced with generating software to convert machine readable data to fit new expanded code structures as new hardware is procured.

Software for applications must be the responsibility of the library systems group. In a large system contractors may be employed to write certain software as specified by the library. Strict control must be maintained, however, to assure a successful end product and the library's ability to take over maintenance of such programs once installed. This will be one of the most challenging administrative areas for project management in development of the library's online system.

\section{GEOGRAPHIC IMPLICATIONS}

Both national and local geographic implications result from the installation of on-line computer-based systems in large research libraries. National implications, of course, depend upon the role the library chooses in its relation to a national information network. The application of computers on a batch mode to libraries has brought about the possibility of increased cooperation beyond merely interlibrary loan services. Swapping of basic bibliographic information and access to greater index facilities is now possible by construction of suitable on-line communications systems permitting remote queries to search another library's catalogs. Therefore, on a national basis, large research libraries will send and receive queries to search their data base. Thus, some information needs will be met without intervention of more than one librarian in the originating library. This can mean an immense saving in man-hours and effective provision of additional reference librarians without the addition of extra staff.

On a local level implications of online systems techniques will completely change the present trend of library science toward centralization of processing activities. With centralized processing and subsequent dissemination of the physical volumes to scattered physical locations, cumbersome order and inprocess files are created, as well as manual material sorting operations, and routing of materials to many people, to name only a few salient characteristics. Computer-based batch processing has encouraged this centralization trend to economically justify computer use, maintain audit control of the work processed, and build suitable clerical support necessary for a computer-based system. The advent of on-line techniques has made it possible to remove all the delay and inefficiencies of either a manual or centralized batch processing mode system. Because of the ability to query a central data bank, with file security provisions built into the system, along with memory protection, it becomes more desirable to structure large library systems for decentralized acquisitions and processing. This would elim- 
inate the physical routing of volumes, cut the cataloging time, and yet give the advantages of centralization without the disadvantages. Branch libraries for geographic or subject areas could be built to be serviced more fully than oneman departmental libraries could ever be serviced, by providing longer open hours, more professional help to the user, and more timely delivery of new materials.

In such a decentralized system, each individual branch would have equal access to query the central data bank. It would be able, however, to change or add to only its designated portion of the file. Through security and access codes only appropriate personnel could query levels of management information. File accuracy would be the responsibility of the individual branch library working together with an audit section of the library's systems group, each library having one representative responsible for solving errors or file problems when they occur. This audit pool technique as the human interface between error checking software and the individual user of the system has proved effective in many large corporations operating time-sharing systems. In this environment many different departments maintain such liaison personnel to take care of problems.

To summarize, on-line query would give the geographically decentralized library system the advantages of centralization because of the central data bank of information. It would effectively combine the advantages of smaller libraries and decentralized physical processing activities. The disadvantage of cumbersomeness on the part of centralization of manual activities would not exist. Secondly, the disadvantage of split records, ineffective procedural control, and lack of the right operational information in the right physical location would cease to be a problem. For better serv- ice and staff utilization such an on-line system would aid the library administrator effectively to extend and increase service.

\section{USER SERVICES}

One of the most perplexing problems for the user of a large research library is the complexity of finding information rapidly and receiving current information only after delays of six months to a year from its publication. Some reference requests may involve much physical travel between various departments of the library system, even just to find out whether a certain book is in a particular department. Finding locations of the actual material, once promising bibliographic references have been located, consumes much valuable time for user and library staff. In the typical large research library reference help is limited and the user is forced to fend for himself, much of the time inadequately. Librarians wish to alleviate this situation, but because of limited staff, certain antiquated procedures, and lack of the proper files in the right places, progress in solving this problem is slow.

Use of modern indexing services and techniques, a redefinition of reference service goals, and the design of thoroughly modern on-line systems designed to free librarians for the most important task in the library-the provision of adequate reference service-will alleviate the situation described above. By using such centrally procured services as MARC and MEDLARS, the library will capture basic bibliographic information for a large percentage of references at the time of their order. Upon receipt of an order this information will be added to for more rapid processing of new items. Other factors, such as publisher's standards, title page standards, universal book numbers, and further delineation of various record types to handle publication types not covered by 
MARC, will undoubtedly be implemented in the coming years.

\section{Library Staff Effects}

Staff members in most large research libraries are familiar with what computer systems may do for the library, either through direct experience or through related professional activities. Every library should have a program of in-service education in this area to lay groundwork for systems work being done in the library without arousing apprehensions among staff. With this point in mind, on-line systems should have a positive effect on all staff members if the system's capabilities are understood. Library staff must be made to feel a part of any systems development which takes place in their library since they place the requirements in the hands of the system designers.

It is said that many librarians are utilized in libraries for work more properly performed by senior clerical personnel. If it be true, their retraining may become a necessity and their employment as librarians in future years called in doubt unless they are utilized to provide reference, indexing, acquisitions, or in managerial functions. Much less professional staff and more clerical staff within the library itself will need to be concerned with purely processing work. This will permit more librarians to be engaged in the much more creative and professional task of helping the library user to solve his information problems in depth.

Librarians should feel much more in control of their libraries, because of the availability of basic information throughout the system, ease of handling many routine requests, time to manage effectively, to decide acquisitions, and to make full use of centrally procured preprocessing information. Librarians may turn their fullest attention to the design and provision of new services such as in-depth reference searches, selective dissemination, or other custom tailored information routing. Through effective systems groups trained to develop and maintain the library's computer-based systems, a high confidence level should be achieved among the whole library staff.

\section{Conclusion}

As always, librarians are striving to provide increased service to their clientele who increase in number as well as sophistication in their service expectations. On-line systems will do much to make library use easier for the patron and less time-consuming on both his part and the library's; it will also provide a base for the development of national library networks. When each large research library has basic bibliographic data machine-readable and serviced by on-line systems permitting remote query between geographically separated computer systems, quicker information processing will result for the information user. A depth of resources will be made available to every library on a faster basis than through the present complex procedures of writing or teletype communication and subsequent checking operations performed on each request no matter how routine in nature.

Librarians will be free to decentralize their collections yet retain the efficiencies of centralized processing and record systems. Rapid copy service, facsimile transmission, microfiche dissemination, and many other techniques will be employed to expand library services to an ever more demanding user group. The system work to now and that planned for the immediate future should effectively prepare the large research library for the development of on-line computer-based record systems for information processing and dissemination. Systems librarians face a great challenge to put together well designed systems and effectively communicate the library's needs to the library's computer center personnel. 